\title{
Support/Promote Physical and Mental Health of Foreigners in
}

\section{Japan \\ (presented and discussed in English)}

\author{
Organizer \\ Yuko YAMAMIYA (Temple University, Japan Campus/Ochanomizu University) \\ Chair \\ Yuko YAMAMIYA (Temple University, Japan Campus/Ochanomizu University) \\ Presenters \\ Joohna PARK (Nagoya University of Commerce and Business) \\ Michael Nevans (TELL Counseling Center) \\ Yuko WATABE (Temple University, Japan Campus) \\ Discussant \\ Satoko KIMPARA (Palo Alto University)
}

\section{Introduction: The Current Situation of Healthcare-Related Issues of Foreigners Residing in Japan.}

Yuko YAMAMIYA (Temple University, Japan

Campus/Ochanomizu University)

The number of foreigners who reside in Japan is rapidly increasing. According to the Ministry of Justice (2018), more than 2.4 million foreigners resided in Japan in 2017, which is the highest number in the Japanese history. However, as Japan is the only country that speaks Japanese as the national language, they do not speak Japanese as their first tongue. Moreover, Japan is a collectivistic culture where people conform to social norms. Therefore, it is almost inevitable for foreigners moving to Japan to experience difficulties adjusting and adapting to Japanese lifestyle, customs, and culture. While some people may acculturate relatively easily, others may experience great stress, which often leads to various health problems (both mental and physical).

However, many foreigners in Japan do not take any action even when they acknowledge that they need a medical help. A recent qualitative research (Koyama et al., 2017) shows that two major reasons why they are reluctant to seek medical services in Japan are (1) cultural difference and (2) language barrier. Thus, assisting foreigners with acculturation and language may result in their obtaining adequate medical services when necessary. As we expect the further increase of foreigners moving to Japan in the future, promoting and supporting their mental and physical health may be an important mission for JAHP. This symposium will offer professionals in health psychology the recent knowledge regarding the current health-related issues of and treatment approaches for foreigners residing in Japan. The symposium will be English and there is no potential COI to disclose in all the following presentations.

Migrants' Workplace Adaptation as an Acculturation Process: A Qualitative Examination of South Korean Workers.

Joonha PARK (Nagoya University of Commerce and Business), Geonsil LEE (Public Health Research Foundation)
As a consequence of globalisation, work-induced mobility and economic migration across national borders have been increasing over the past decades (Carr, 2010). In contrast to the past tendency where most migrant workers were involved in unskilled and low-wage occupations (Iguchi, 2014; Komai, 1997), today, there is increasing national interest in highly qualified migrant workers for securing professional human resources in the globalizing society. In this presentation I present a recent study that examined migrant workers' job adjustment processes and stress factors in Japan (Lee, Park, \& Ban, 2016).

Five men and three women (average 32.8 years old, ranging from 28 to 38 years) participated in a series of semi-structured interviews. Data from the interviews were analyzed by adopting Grounded Theory Approach (Strauss \& Corbin, 1999).

Among acculturation-related stress factors (acculturation and adjustment to a new culture, life events, and job and workplace adjustment), the last aspect was further categorized into three: job demand, relationship formation, and company climate, consistent with the previous findings about job stress (Eguchi et al., 2012). Different from local workers, the migrant participants considered cultural aspects to be imbedded in each stressor and felt more uncomfortable and incompetent in dealing with them for this reason. Also, participants showed strong motivation to maintain their national identity, which could cause an additional psychological discomfort based on psychological dilemmas between one's acceptance of integration and motivation for separation (Berry, 1997). Nevertheless, migrants' clear sense of purpose in terms of working in Japan played a critical role in their ability to cope with the acculturation- and job adjustment-related problems.

The study illuminates both general and culture-specific stress factors surrounded in Japanese organization. Furthermore, the findings imply that Japanese colleagues' cross-cultural understandings can serve a preventive approach to caring mental health of migrant workers and improving diversity in their work climate. This is consistent with that positive attitudes toward 
understanding other cultures than their own and interacting with other cultural groups among people in a dominant culture give positive effects on migrants' acculturation (Berry, 1997, 2006).

\section{Healthcare Services for Foreign Workers in Japan.}

Michael NEVANS (TELL Counseling Center)

Living and working in a foreign country can be both one of the most challenging and most rewarding experiences. The stress of adjusting to living in a new environment, interacting with new colleagues, and adapting to new customs, all while dealing with typical life stressors can be overwhelming for some foreign workers in Japan. At TELL Counseling, $30 \%$ of our clients $(65 \%$ non-Japanese) cite anxiety as the primary reason they sought treatment. Although these cases vary in quality and severity, the most commonly reported source of the anxiety is the workplace. In order to better meet the needs of our community, TELL has spent the last year consulting with various HR managers from foreign companies operating in Japan, surveying the needs of their workers. Through our conversations with management and employees at various levels, we found that most people were concerned with the stress that accompanied increased demands as well as how that stress impacts both their work performance and personal life. We also found that most foreign employees did not know how to access healthcare services. Among those who did know how to access services, they were concerned that they could not be adequately helped due to language barriers or cultural misunderstandings of their presenting concerns. It is our hope that through this presentation TELL can provide information from our small sample of foreign HR teams that can further illuminate the needs of the foreign, non-Japanese speaking workers in Japan.

\section{School-Wide Support for Struggling Foreign Students.}

Yuko WATABE (Temple University, Japan Campus)

Temple University Japan Campus (TUJ) is recognized as a Foreign University in Japan by Japan's Ministry of Education, Culture, Sports, Science and Technology. Our students come from approximately 60 countries around the world, including Japan, the United States, East and Southeast Asia, Russia, the Middle East, Africa, Latin America, and Europe. The student body consists of approximately $40 \%$ Japanese students, $40 \%$ American students, and 20\% students from other countries.

Our foreign students who seek support from the University Counseling Services exhibit various mental health issues due to difficulty adjusting to Japanese culture, language barrier, struggles with different societal support and systems, as well as homesickness and isolation. Interestingly, the most frequent complaint related to culture shock from our students is their discomfort of "being stared at" by Japanese people in public.

At TUJ, we provide support through multiple avenues. We provide individual therapy sessions to students and refer students to other departments within TUJ such as Disability Resource Services (DRS), as well as outside agencies for support groups, psychiatric medication assessment, and other resources. Furthermore, TUJ organizes a multidisciplinary team, called CARE, which consists of professionals from different disciplines (i.e., academic advisor, DRS coordinator, student service director, professor, and associate dean). The team takes referrals from faculty and staff about struggling students. The aims of CARE team include the early detection of students in distress, and collaboratively develop support plans and recommendations for the well-being of our students. A case illustration of how our school-wide support system works will be demonstrated during the presentation.

\section{Discussant Points.}

Satoko KIMPARA (Palo Alto University)

Cultural contexts and shared worldview from the clients are ultimately important in psychotherapy to cultivate the clients' worldview and real-life experiences (e.g., Beutler, 2009; Norcross, 2011; Sue, 2002). The physical/mental health providers are sensitive to explore clients' cultural knowledge, shared beliefs, values, and symbol and to adapt clients' preference of languages, gender, religion etc., and if necessary, the physical/mental health providers make a referral to match the culturally sensitive and adaptive services. However, these cross-cultural findings may require investigators to consider the importance of individual differences that exist within their cultures. While considering above points, we will discuss presented issues/key-findings after the presentations.
(YAMAMIYA Yuko, PARK Joohna, NEVANS Michal, WATABE Yuko, and KIMPARA Satoko) 